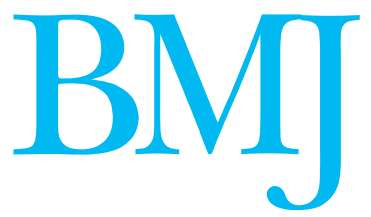

\title{
Patient choice in the NHS
}

\author{
Having choice may not improve health outcomes
}

$\mathrm{I}$ $\mathrm{n}$ the run up to the next general election greater choice for patients over where to be treated is emerging as the big political idea. Ironically, while choice is being promoted in health care, there seems to be very little to choose between the two main political parties on this aspect of health policy. Last week the secretary of state for health, John Reid, announced an expansion of the Labour government's choice programme-and his Conservative opposite number, Andrew Lansley, did the same. ${ }^{2}$ However, look closely and some differences start to emerge. But will the power to choose really improve health outcomes for all?

By 2008, the government says that every patient who needs to be referred by their general practitioner (such gatekeeping is to be retained) for a specialist outpatient consultation will have the choice of any NHS or private provider, or any one of the new treatment centres that are often run as public-private enterprises. ${ }^{3}$ The Conservatives' choice policy is remarkably similar. The difference emerges over how patients' choices are to be funded and, in particular, how private providers are to be paid for treating NHS patients.

The government has said that private providers treating NHS patients will be paid the same fees as NHS hospitals-based on a "money following patient" system of fixed national tariffs. ${ }^{4}$ Such a payment system effectively challenges the private sector to reduce its costs if it wants to do business with the NHS

But the Conservatives are offering to pay private hospitals half the national tariff, with patients picking up the rest of the private fee. This reduces the price to patients and may prove attractive for many people who have not previously been able to afford private care. But it will also provide a (partially) free ride for those who would use private care anyway-an estimated cost to the Exchequer of around $£ 1.2 \mathrm{bn}^{5}$ and equivalent to treating around one million inpatients in the NHS. Of course, the offer will not benefit people who cannot afford the difference between the subsidy and the full fee. Nor will it provide an incentive to the private sector to reduce its costs. At the extreme it could simply encourage price rises, up to the point where the subsidy is absorbed by private providers.

Such differences aside, how either version of patient choice is to work in practice remains hazy. Choosing your outpatient department is not necessarily the same as choosing your inpatient care, for example. Whether patients are to get a further opportunity to choose once they know they need to be admitted is eral practitioners) will decide on their hospital. Waiting times were the only criterion in choice pilots such as the London Patients Choice Project. ${ }^{6}$ But as waiting times decrease (and given both parties' pledge for a maximum wait of 18 weeks from referral to admission), other factors will increasingly loom large-not least the quality of care. But where is the information patients need to judge quality?

Uncertainties exist too about how powerful an incentive mechanism patient choice is to be allowed to be. ${ }^{7}$ Will hospitals that lose patients beyond some critical point be allowed to go to the wall? How will we know whether those patients who choose not to choose are not doing so because they are, for example, unhappy about travelling? How is equality of opportunity of choice to be ensured or defined? And how are popular hospitals to ration their services given short term restrictions on capacity?

Choice is largely instrumental-a means to the end of good quality care. But to what extent can choice really lever up quality? For both parties money following patients should, in theory, prompt providers of acute care to improve the quality of service. For the Conservatives, this will be the major force for improving performance, and targets will no longer be needed. Put simply, free the hospitals and give the public choice and the market will do the rest. But Labour are less sanguine about such market mechanisms and will continue to rely on other ways to improve performance such as central standards and targets, continued investment (funds and staff in particular), more effective regulation, and a different mix of incentives. ${ }^{18}$

Overall, much of the debate and the political rhetoric about choice has been narrowly focused; couched in terms of competition or the threat of competition (contestability), markets (of a sort), and supply side incentives. ${ }^{8}$ What is missing is a broader view of choice $^{910}$ : to most NHS patients, choice of hospital is not always relevant-for example, those with chronic conditions ${ }^{11}$ or needing acute emergency care or those who cannot travel far. Choice also needs to encompass ideas of patient empowerment and a more collaborative approach between patients and professionals when it comes to making often difficult clinical decisions.

John Appleby chief economist

(j.appleby@kingsfund.org.uk)

Jennifer Dixon policy director

(j.dixon@kingsfund.org.uk)

King's Fund, London W1G 0AN 
Competing interests: None declared.

1 Secretary of State for Health. The NHS improvement plan:putting people a the heart of public services. London: Stationery Office, 2004. (Cm 6268. www.dh.gov.uk/assetRoot/04/08/45/22/04084522.pdf (accessed 28 Jun 2004).

2 Conservative Party. Right to choose. June 2004. www.conservatives.com/ getfile.cfm?file = rightochoose\&\&ef $=$ POLICYDOCUMENT/ 1664\&type $=$ pdf $($ accessed 28 Jun 2004)

3 Department of Health. Reid launches new NHS improvement plan. Press release (2002/0232), 24 June 2004. www.dh.gov.uk/ PublicationsAndStatistics/PressReleases/PressReleasesNotices/fs/ en?CONTENT ID = 4084528\&chk= IFY1cL (accessed 28 Jun 2004).

4 Department of Health. NHS reference costs 2003 and national tariffs 2004 (payment by results). London: DoH, 2004.
5 Conservative Party. Right to choose: Health:questions and answers.June 2004. www.conservatives.com/policies/policy.cfm?obj id $=107037$ (accessed 28 Jun 2004)

The London Modernisation Board. Modernising London's NHS: London patients choice project: project overview. London: London Modernisation Board, 2004. www.london.nhs.uk/patientchoice/ (accessed, 28 Jun 2004). 7 Appleby J, Devlin N, Deeming C, Harrison A. This little piggy.... Health Serv J. 2002;112,5818:24-9.

8 Stevens S. Reform strategies for the English NHS. Health Affairs 2004;23,3:37-44.

9 Blackwell N. Better schools and hospitals: why parent and patient choice will work. London: Centre for Policy Studies, 2004. 10 Appleby J, Harrison A, Devlin N. What is the real cost of more patient choice?

11 Dixon J, Lewis R, Rosen R, Finlayson B, Gray D. Can the NHS learn from US managed care organisations? BMJ 2004;328:223-5.

\section{Non-parenteral vaccines}

\section{Have not lived up to their initial promise because of side effects}

$\mathrm{V}$ accination is potentially the most cost effective method of controlling infections. ${ }^{1}$ However, as the quests for safe and effective anti-HIV and anti-malarial vaccines show, successful development of vaccines is not easy. When HIV was identified, optimists thought that a vaccine would soon follow, perhaps within two years. Two decades later, that goal seems to be as elusive as ever. Moreover, worldwide eradication of a disease-although possible, as shown with smallpox-presents logistic and economic challenges. People who need the vaccines are most often least able to pay for them or use them properly, because of educational barriers or woefully inadequate healthcare systems.

Most vaccines are administered by injection. Effective non-parenteral vaccines would be more convenient and potentially cheaper to produce and administer. Why then are so few such vaccines available? For example, in the United Kingdom, despite intense research, only the Sabin oral polio vaccine is in general use. In a survey of the field nine years ago I was optimistic and foolhardy enough to believe that soon many of the parenteral vaccines would be administered via alternative routes. ${ }^{2}$

With better understanding of the immune system, notably at mucosal portals of entry, recognition of the common mucosal immune system, rapid development of genetic engineering techniques, and the human genome project, increasing political pressure for methods to control the HIV, and the excitement of the researchers involved, one could easily be mesmerised. Yet, the debates about the relative merits of the oral and parenteral polio vaccines should have tempered our excitement. ${ }^{3}$ For non-parenteral vaccines to work, the antigen or vaccine has to breach the defensive mucosal barriers, rich in proteolytic enzymes and resistant to the passive diffusion of proteins. This can be done by identifying active carrier systems or, more practically, by damaging the barrier membranes through use of either erosive formulation additives or invasive attenuated bacteria or viruses. Both approaches are potentially toxic. Mutation of attenuated micro-organisms back to pathogenic variants, including the wild type, may have devastating effects: outbreaks of iatrogenic poliomyelitis associated with the use of the oral polio vaccine, for example, are well known. ${ }^{3}$

Recognition that traces of novel adjuvants, notably enterotoxins (cholera enterotoxin (CT) and heat labile enterotoxin (LT)) produced by Vibrio cholerae and Escherichia coli, respectively, improved the immune response to mucosal vaccines to an extent that implied clinical effectiveness, created considerable optimism. ${ }^{5}{ }^{6}$ This optimism was partly justified as two non-parenteral vaccines, an oral vaccine against the rotavirus and an intranasal vaccine, with heat labile Escherichia coli enterotoxin as adjuvant against influenza were subsequently marketed. ${ }^{78}$ Both vaccines, however, were withdrawn soon after as a result of adverse effects-Bell's palsy in the case of the anti-influenza vaccine $e^{7}$ and intussusception in the case of the anti-diarrhoeal vaccine. ${ }^{8}$

A safety study of the Swiss influenza vaccine in 2000 identified Bell's palsy as a possible adverse effect (9 in 3600 subjects studied). In the early postmarketing stage (October 2000 to March 2001), with about 90000 vaccinated subjects, five cases were reported spontaneously. ${ }^{9}$ By April 2001, this had increased to 46. A subsequent case-control study estimated that in contrast to the parenteral vaccine, the intranasal formulation increased the risk of Bell's palsy considerably (adjusted odds ratio 84, 95\% confidence interval 20 to 352$){ }^{7}$ It was estimated conservatively that 13 excess cases occurred per 10000 subjects vaccinated. These figures show how inefficient spontaneous adverse reporting is for identifying even specific and severe adverse reactions.

Five cases of intussusception were seen among 10054 infants who received the rotavirus vaccine, compared with one among the 4633 subjects in the placebo group. ${ }^{10}$ In a case-control study, the incidence rate ratio was estimated at $29(95 \%$ confidence interval 16-54) within two weeks of the first dose. The second dose increased the risk more modestly. Overall, there was one case of intussusception attributable to the vaccine for every 4670 to 9474 infants vaccinated.

What lessons can then be learnt from those vaccine withdrawals? Firstly, all vaccines carry with them some risk of adverse effect that needs to be balanced against their potential benefits. Secondly, for diseases for which 